\title{
Streaming potentials at hydrocarbon reservoir conditions
}

\author{
J. H. Saunders ${ }^{1}$, M. D. Jackson ${ }^{1}$, M. Y. Gulamali ${ }^{1}$, J. Vinogradov ${ }^{1}$, and C. C. Pain ${ }^{1}$
}

\begin{abstract}
We have examined the behavior of the streaming potential under multiphase conditions, and under conditions of varying temperature and salinity, to evaluate the feasibility of using downhole streaming-potential measurements to determine fluid distributions in a reservoir. Using new insights into the pore-scale distribution of fluids and of electric charge, we found that the saturation dependence of the streaming potential coupling coefficient is important in determining the resulting streaming potential. Through examination of the four independent physical parameters which comprise the coupling coefficient, we developed an understanding of the behavior of the coupling coefficient under conditions of elevated temperature and brine salinity. We found that although increasing salinity substantially reduces the magnitude of the coupling coefficient, and therefore also the magnitude of the predicted streaming potential, increasing temperature has only a small effect, showing about a $10 \%$ change between $25^{\circ} \mathrm{C}$ and $75^{\circ} \mathrm{C}$, depending on salinity.
\end{abstract}

\section{INTRODUCTION}

Streaming potentials in porous media have their origin in the electric double layer which forms at solid-fluid interfaces when an electrolyte such as brine reacts with the mineral surface (Hunter, 1981; Revil et al., 1999). The mineral surface becomes electrically charged (typically negatively in quartz-brine systems) and a diffuse layer containing an excess of (typically positive) countercharge is formed in the adjacent fluid, giving zero net charge when the rockfluid system is at rest (Wyllie, 1951; Ishido and Mizutani, 1981). If the fluid is induced to flow tangentially to the interface by an external pressure gradient, some of the excess charge within the diffuse layer is transported with the flow, giving rise to a streaming current. Accumulation of charge associated with divergence of the streaming current density establishes an electric potential, termed the streaming potential.

Recent numerical modeling work has suggested that measurements of streaming potential, acquired using electrodes permanently installed downhole, could be used to monitor water saturation changes in the vicinity of a well during oil or gas production (Saunders et al., 2006, 2008). The streaming potential is due to inflow of water to the reservoir as the hydrocarbons are extracted, either from an underlying aquifer or from water injection wells. The key findings from this earlier work were

1) The potential is a maximum at the water front, and at geologic boundaries where the water saturation changes. As water encroaches on the production well, the streaming potential associated with the water front is predicted to encompass the well when the front is up to $100 \mathrm{~m}$ away, so the potential measured at the well would start to change relative to a distant reference electrode,

2) Variations in the geometry of the encroaching water front could be characterized using an array of electrodes positioned along the well, although a good understanding of the local reservoir geology would be required to identify signals caused by the front,

3) The streaming potential measured at the well is maximized in low permeability reservoirs produced at a high rate, and in thick reservoirs with low shale content.

These findings raise the prospect of real-time monitoring of flow at considerable distance from a well, and of an informed feedback process between monitoring and inflow to the well to enhance production. However, as pointed out by Saunders et al. (2008), considerable uncertainties remain, particularly relating to the nature of the streaming-potential coupling coefficient in the high salinity and temperature conditions typical of hydrocarbon reservoirs, and during multiphase flow.

The streaming-potential coupling coefficient $C\left(\mathrm{~V} \mathrm{~Pa}^{-1}\right)$ is the macroscopic petrophysical property which relates fluid and electric potential gradients (Sill, 1983). It is well-known that the

\footnotetext{
Manuscript received by the Editor 16 February 2011; revised manuscript received 29 July 2011; published online 13 February 2012.

${ }^{1}$ Imperial College London, Department of Earth Science and Engineering, London, U. K. E-mail: jon.saunders@ @imperial.ac.uk; m.d.jackson@imperial.ac.uk; m.gulamali@imperial.ac.uk; j.vinogradov@imperial.ac.uk;c.pain@imperial.ac.uk.

(C) 2012 Society of Exploration Geophysicists. All rights reserved.
} 
magnitude of the coupling coefficient decreases with increasing brine salinity and, based on data available at the time, Saunders et al. (2008) predicted that the streaming potential measured during production may become too small to resolve $(<0.1 \mathrm{mV})$ if the salinity of the formation brine is higher than that of seawater, c. $0.6 \mathrm{~mol} \cdot \mathrm{L}^{-1}$. Moreover, Saunders et al. (2008) also suggested that the magnitude of the streaming potential may decrease with increasing temperature, principally because of the increased brine conductivity. Consequently, it is still not clear whether streaming potentials would be measurable in many hydrocarbon reservoirs. Moreover, only one reservoir and production scenario has been investigated to date.

The first aim of this paper is to investigate the behavior of the streaming-potential coupling coefficient at salinity and temperature conditions typical of hydrocarbon reservoirs, and during multiphase flow. A detailed study of the temperature dependence of the streaming-potential coupling coefficient and its component parts by Reppert and Morgan (2003a, 2003b) shows the difficulty of attempting to determine any generalized relationship due, in particular, to the dependence of the zeta potential (the electric potential associated with the electric double layer at the mineral-water interface) on a multiplicity of microscopic properties of the electrolyte and the mineral surface. However, for silica surfaces in contact with predominantly $\mathrm{NaCl}$ brine (the situation in most hydrocarbon reservoirs) the zeta potential is observed to increase with temperature (Ishido and Mizutani, 1981; Revil et al., 1999). Here we follow a procedure complementary to that of Reppert and Morgan (2003a), examining each of the components of the streaming-potential coupling coefficient and its dependence on both temperature and salinity, and using this information to develop a model for the coupling coefficient. The electric conductivity, viscosity, and permittivity of the formation water have well-known relationships to salinity and temperature. We propose a modified model for the salinity dependence of the zeta potential including the high salinity range, using the model of Revil and Glover (1997) and recent experimental data from Vinogradov et al. (2010). The saturation dependence of the streaming-potential coupling coefficient is described using models from Guichet et al. (2003), Revil et al. (2007) and Jackson (2010) together with recent experimental data (Vinogradov and Jackson, 2010).

The second aim of the paper is to investigate the utility of streaming-potential measurements in a wider range of reservoir and production scenarios than have been considered to date. Saunders and coworkers (Saunders et al., 2006, 2008) use a model based on that described by Wurmstich and Morgan (1994), who were the first to discuss the use of streaming potentials for monitoring changes in fluid distribution during production. This model consists of a single vertical well producing oil from a horizontal sandstone reservoir layer with water encroaching from one side. In a simple sensitivity analysis, Saunders et al. (2008) vary the reservoir thickness, permeability and spatial permeability variation, and the distribution of nonreservoir shales within the sandstone reservoir interval to investigate the influence of these parameters on the simulated streaming potential at the well. Here we use that model in light of our improved understanding of the streaming-potential coupling coefficient in reservoir conditions, but also model a horizontal well producing from a thin oil column within a sandstone reservoir, with water encroaching from below. Early water breakthrough in this production scenario is a key risk, because the well can be killed if the higher density water cannot flow to surface. Moreover, in this well we can be confident about excluding the contributions from electrochemical or thermoelectric effects (Gulamali et al., 2011) because the temperature gradient over the extent of the oil column is typically small (c. 1-2 K) and the salinity of the aquifer replacing the reservoir fluids is typically very similar to that of the residual brine in the reservoir itself. We investigate the predicted streamingpotential measurements resulting from production from a single horizontal well with multiple completions. This is a first step toward developing a feedback control strategy (Addiego-Guevara et al., 2008), which may be used to enhance production.

\section{THEORETICAL BACKGROUND}

\section{Governing equations}

Equations governing the flow of two immiscible fluids through a porous medium and the coupled equations describing the resulting (low-frequency component of) streaming potential are described in Saunders et al. (2008) and elsewhere (e.g., Aziz and Settari (1979); Sill (1983). We assume that the wetting phase (subscript $w$ ) is $\mathrm{NaCl}$ brine, the nonwetting phase (subscript $n w$ ) is a nonpolar oil, that only the wetting phase contributes to the streaming potential and we neglect the contribution of the electric double layer at the fluid-fluid interface. In hydrocarbon reservoirs with relatively clean sand $(<10 \%$ clay content) saturated with moderate- to high-salinity brine $\left(>0.5 \mathrm{~mol} \cdot \mathrm{L}^{-1}\right)$, the contribution of surface conductivity may be neglected (Schoen, 2004; Mavko et al., 2009), and we define the streaming-potential coupling coefficient in fully brine-saturated conditions $\tilde{C}$ using the classical Helmholtz-Smoluchowski equation

$$
\tilde{C}=\frac{\zeta \epsilon_{w}}{\eta_{w} \sigma_{w}},
$$

where $\zeta$ is the zeta potential, $\epsilon_{w}$ the brine permittivity, $\eta_{w}$ the brine viscosity and $\sigma_{w}$ the brine conductivity.

The fluid problem is solved using the Eclipse 100 finite-volume reservoir simulator. The electric problem is solved using the open-source finite-element CFD code Fluidity (Piggott et al., 2008; Saunders et al., 2008).

\section{Salinity and temperature dependence of the streaming-potential coupling coefficient $C$}

We begin by considering the temperature and salinity dependence of the streaming-potential coupling coefficient in fully brinesaturated conditions. By understanding the behavior of each of the terms in equation 1, we can develop a model for the streaming potential coupling coefficient under varying salinity and temperature conditions. The range of interest for temperature $T\left({ }^{\circ} \mathrm{C}\right)$ and brine salinity $C_{f}\left(\mathrm{~mol} \cdot \mathrm{L}^{-1}\right)$ in hydrocarbon reservoirs is $20<T<150^{\circ} \mathrm{C}$, and $0.01<C_{f}<5.0 \mathrm{~mol} \cdot \mathrm{L}^{-1}$, with typical values in the range $60<T<100^{\circ} \mathrm{C}$, and $0.5<C_{f}<2.0 \mathrm{~mol} \cdot \mathrm{L}^{-1}$. We assume that $\mathrm{NaCl}$ is the only salt species present. The temperature and salinity dependence of the zeta potential, brine permittivity, viscosity, and conductivity are presented in Appendix A.

Normalizing each parameter in equation 1 by its value at $25^{\circ} \mathrm{C}$ (Figure 1) we can see that between $25^{\circ} \mathrm{C}$ and $75^{\circ} \mathrm{C}$ permittivity decreases by approximately $19 \%$, viscosity decreases by approximately $57 \%$, and conductivity increases by approximately $105 \%$. At low salinity $\left(0.01 \mathrm{~mol} \cdot \mathrm{L}^{-1}\right)$ zeta potential increases by 
approximately $18 \%$, giving an overall increase in $C$ of $9 \%$, while at seawater salinity $\left(0.6 \mathrm{~mol} \cdot \mathrm{L}^{-1}\right)$ zeta potential is constant, so $C$ decreases by almost $8 \%$ (Figure 2). The salinity at which the behavior of $C$ changes depends on the maximum packing of ions in the diffuse layer. Based on the data of Vinogradov et al. (2010), the threshold salinity appears to lie between 0.3 and $0.6 \mathrm{~mol} \cdot \mathrm{L}^{-1}$. Although the influence of temperature is small, the resulting streaming-potential coupling coefficient decreases strongly with increasing salinity.

\section{Multiphase behavior of $C$}

When a second fluid phase is present in the pore space, the magnitude of the streaming-potential coupling coefficient becomes dependent on a number of factors including the wettability of the rock, the composition of the pore fluids, and the saturation of each phase (Jackson, 2010). In the simplest case the nonwetting phase is nonpolar and its flux causes no streaming current. The streaming-potential coupling coefficient then depends on the saturation of the wetting phase (assumed here to be water/brine) and may be expressed in terms of the coupling coefficient in fully

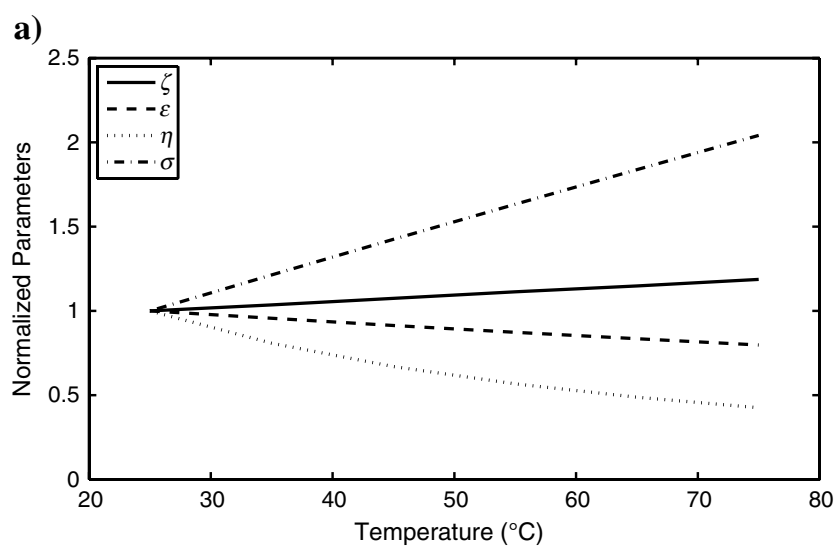

b)

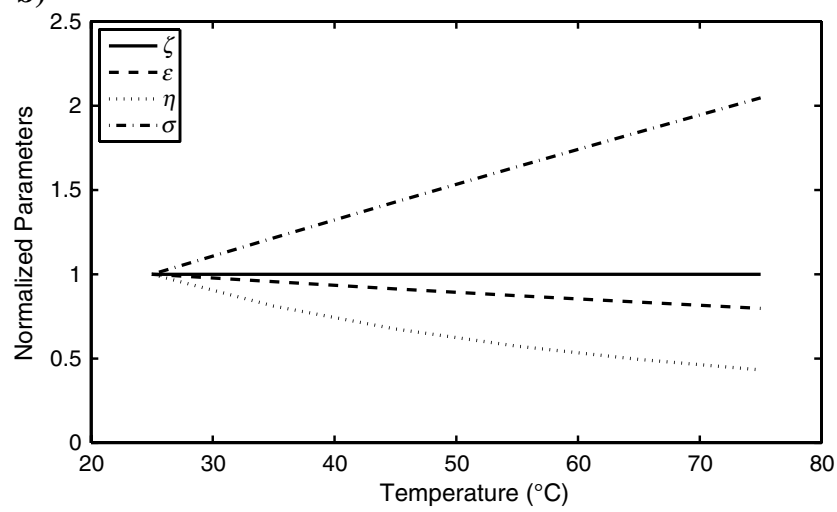

Figure 1. Predicted values of zeta potential, dielectric permittivity, viscosity, and conductivity normalized by their values at $25^{\circ} \mathrm{C}$ and plotted against temperature for two salinities. (a) Here, $0.01 \mathrm{~mol} \cdot \mathrm{L}^{-1}\left(\zeta=-28.4 \mathrm{mV}, \epsilon_{w}=7.81 \times 10^{-10} \mathrm{Fm}^{-1}, \eta_{w}=\right.$ $8.91 \times 10^{-4} \mathrm{~Pa} \cdot \mathrm{s}$ and $\sigma_{w}=0.118 \mathrm{~S} \cdot \mathrm{m}^{-1}$ at $\left.25^{\circ} \mathrm{C}\right)$ and (b) $0.6 \mathrm{~mol} \cdot \mathrm{L}^{-1} \quad$ (seawater, $\zeta=-17.0 \mathrm{mV}, \quad \epsilon_{w}=6.75 \times$ $10^{-10} \mathrm{Fm}^{-1}, \eta_{w}=9.37 \times 10^{-4} \mathrm{~Pa} \cdot \mathrm{s}$ and $\sigma_{w}=5.42 \mathrm{~S} \cdot \mathrm{m}^{-1}$ at $25^{\circ} \mathrm{C}$ ). See Appendix A for discussion of permittivity values at high temperature and salinity. brine-saturated conditions $\tilde{C}$, and a saturation-dependent relative coupling coefficient $C_{r}$ (analogous to a relative permeability)

$$
C=\tilde{C} C_{r}
$$

where (Jackson, 2010)

$$
C_{r}=\frac{k_{r w} Q_{r}}{\sigma_{r}} .
$$

Here, $k_{r w}$ is the relative permeability of the wetting phase, $Q_{r}$ is the relative excess charge density (describing how the charge density of counterions in the fluid changes with wetting phase saturation) and $\sigma_{r}$ is the relative conductivity of the saturated rock. Several models have been proposed for $Q_{r}$ during drainage (see discussion in Jackson, 2010). We will concentrate on models taken from Revil et al. (2007), Jackson (2010), and Guichet et al. (2003) (Figure 3a with $\sigma_{w} \propto S_{w}^{1.65}, k_{r w} \propto S_{w}^{4}$ ) as they enable us to investigate the relative performance of broadly convex and broadly concave $C_{r}$ curves. There are presently no models or data for imbibition except Vinogradov and Jackson (2010), but these data are from experiments with saturations at unsteady-state and so cannot be used here. All three models are adjusted for imbibition to account for the presence of immobile fractions of both the wetting and nonwetting phases $\left(S_{w i}=S_{n w i}=0.2\right)$ and to have endpoints at 0 and 1, by substituting the mobile wetting phase volume fraction $S_{m w}$ for $S_{w}$ in the Guichet model, and by multiplying the Revil and Jackson models by the reciprocal of the original function value at $S_{w}=1-S_{n w i}$ (Figure 3b).

The Revil model then becomes

$$
C_{r}=\frac{k_{r w}}{\sigma_{r} S_{w}} \frac{\tilde{\sigma}_{r}\left(1-S_{n w i}\right)}{\tilde{k}_{r w}},
$$

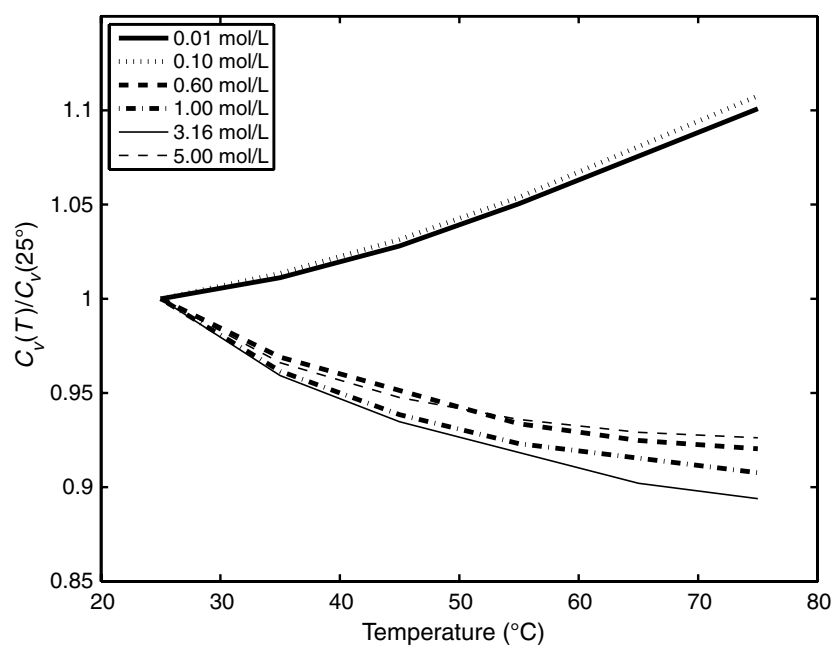

Figure 2. Streaming-potential coupling coefficient relative to its value at $25^{\circ} \mathrm{C}$ plotted against temperature for a range of salinities. For salinities up to $0.1 \mathrm{~mol} \cdot \mathrm{L}^{-1}, C$ increases with temperature, but at higher salinities, the limit on $\zeta$ causes $C$ to decrease with increasing temperature. Values for $C\left(\mathrm{mV} \mathrm{MPa}^{-1}\right)$ at $25^{\circ} \mathrm{C}: 316.1$ $\left(0.01 \mathrm{~mol} \cdot \mathrm{L}^{-1}\right), 19.7\left(0.1 \mathrm{~mol} \cdot \mathrm{L}^{-1}\right), 2.0\left(0.6 \mathrm{~mol} \cdot \mathrm{L}^{-1}\right), 1.15$ $\left(1 \mathrm{~mol} \cdot \mathrm{L}^{-1}\right), 0.22\left(3.16 \mathrm{~mol} \cdot \mathrm{L}^{-1}\right), 0.09\left(5 \mathrm{~mol} \cdot \mathrm{L}^{-1}\right)$. 
where $\tilde{\sigma}_{r}$ and $\tilde{k}_{r w}$ are the relative fluid conductivity and permeability evaluated at $S_{w}=1-S_{n w i}$, i.e., at the maximum possible brine saturation. The Jackson model is given by

$$
C_{r}=\frac{S_{m w}}{\sigma_{r}} \tilde{\sigma}_{r},
$$

with $S_{m w}$ given by

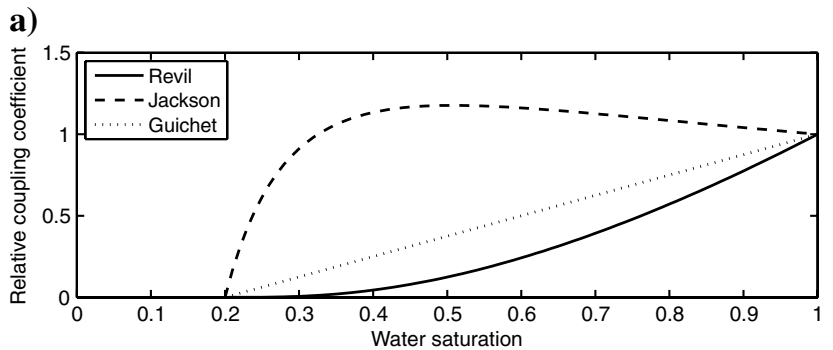

b)

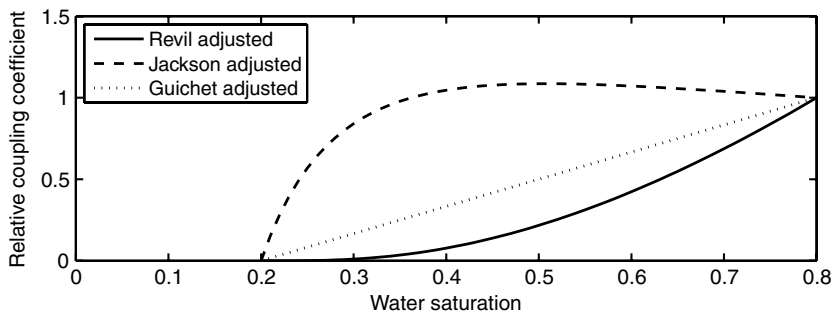

Figure 3. Relative coupling coefficient versus saturation: (a) Models for $C_{r}$ from Revil et al. (2007), Jackson (2010), and Guichet et al. (2003) for drainage, assuming different behavior of the excess charge density with decreasing saturation. (b) The models of Revil et al. (2007) (equation 4), Jackson (2010) (equation 5) and Guichet et al. (2003) (equation 7) adjusted for imbibition and accounting for an irreducible volume fraction of the nonwetting phase, and with endpoints fixed at 0 and 1. Irreducible volume fractions are $S_{w i}=S_{n w i}=0.2$, conductivity $\sigma_{w} \propto S_{w}^{1.65}$ and relative permeability $k_{r w} \propto S_{m w}^{4}$

$$
S_{m w}=\frac{S_{w}-S_{w i}}{1-S_{w i}-S_{n w i}} .
$$

The Guichet model is described by

$$
C_{r}=S_{m w} .
$$

Using $\sigma_{w} \propto S_{w}^{1.65}, k_{r w} \propto S_{m w}^{4}$ and $\left.k_{r w}\right|_{\left(S_{w}=1-S_{n w i}\right)}=0.3$, the models of Revil et al. (2007) and Jackson (2010) present distinct behavior at intermediate saturations, with that of Revil predicting small values of the relative coupling coefficient at intermediate saturation, and the model of Jackson suggesting that the coupling coefficient changes less at high water saturation, but drops sharply as the water saturation approaches the irreducible value. (We note that using $k_{r w} \propto S_{m w}^{2}$ alters the curve of Revil to look more like that of Jackson.) Experimental data from Allègre et al. (2010) supports the idea that the relative coupling coefficient is high (perhaps tens or even hundreds of times the magnitude at saturation) at intermediate saturations.

\section{THE RESERVOIR MODELS}

Two reservoir geometries are used to predict the streamingpotential response during recovery, one vertical well and one horizontal well. Both consist of a single sandstone reservoir bounded above and below by water-bearing shales, and intersected by a single producing well. Their properties are summarized in Table 1. The vertical well model has been used in previous studies (Saunders et al., 2006, 2008), and is based on the model of Wurmstich and Morgan (1994). Here we use an updated understanding of the streaming-potential coupling coefficient in reservoir conditions to improve the predictions made in this earlier work. The horizontal well model has been used in previous studies to investigate and quantify the benefit of reactive feedback control based on measurements of flow at the well (Addiego-Guevara et al., 2008). Consequently, it is a sensible test case to investigate the utility

\begin{tabular}{|c|c|c|}
\hline Property & Vertical well & Horizontal well \\
\hline Dimensions & $1150 \times 500 \times 100 \mathrm{~m}$ & $1800 \times 900 \times 100 \mathrm{~m}$ \\
\hline Horizontal permeability $k_{x, y}$ & $152-1520 \mathrm{mD}\left(1.52 \times 10^{-13}-1.52 \times 10^{-12} \mathrm{~m}^{2}\right)$ & $152 \mathrm{mD}\left(1.52 \times 10^{-13} \mathrm{~m}^{2}\right)$ \\
\hline Vertical permeability $k_{z}$ & $152 \mathrm{mD}\left(1.52 \times 10^{-13} \mathrm{~m}^{2}\right)$ & $3-152 \mathrm{mD}\left(3 \times 10^{-15}-1.52 \times 10^{-13} \mathrm{~m}^{2}\right)$ \\
\hline Oil conductivity & $1 \times 10^{-5} \mathrm{~S} \cdot \mathrm{m}^{-1}$ & $1 \times 10^{-5} \mathrm{~S} \cdot \mathrm{m}^{-1}$ \\
\hline Brine viscosity & $0.001 \mathrm{~Pa} \cdot \mathrm{s}$ & $0.001 \mathrm{~Pa} \cdot \mathrm{s}$ \\
\hline Oil viscosity & $0.001-0.008 \mathrm{~Pa} \cdot \mathrm{s}$ & $0.001 \mathrm{~Pa} \cdot \mathrm{s}$ \\
\hline Brine density & $1000 \mathrm{kgm}^{-3}$ & $1000 \mathrm{kgm}^{-3}$ \\
\hline Oil density & $1000 \mathrm{kgm}^{-3}$ & $800 \mathrm{kgm}^{-3}$ \\
\hline
\end{tabular}
of streaming-potential measurements to characterize flow at a

Table 1. Description of reservoir models. 
distance from a horizontal well in a thin oil column, where early water breakthrough is often observed if no action is taken to prevent it. Deployment of streaming-potential monitoring equipment along a horizontal well may offer maximum benefit in this case.

In the vertical well model (Figure 4a), the sandstone reservoir layer measures $1150 \times 500 \mathrm{~m}$ in plan-view, whereas in the horizontal well model (Figure $4 \mathrm{~b}$ ), the reservoir layer measures $1800 \times 900 \mathrm{~m}$. The sandstone reservoir layer in each case is $100 \mathrm{~m}$ thick and lies between $500 \mathrm{~m}$ and $600 \mathrm{~m}$ depth, with porosity equal to $25 \%$. Permeability is isotropic in the homogeneous vertical well model $\mathrm{V} 1\left(\mathbf{k}=152 \mathrm{mD}=1.52 \times 10^{-13} \mathrm{~m}^{2}\right)$ and anisotropic in the homogeneous horizontal well model $\mathrm{H} 1 \quad\left(k_{x, y}=152 \mathrm{mD}=1.52 \times 10^{-13} \mathrm{~m}^{2}\right.$, $\left.k_{z}=3 \mathrm{mD}=3 \times 10^{-15} \mathrm{~m}^{2}\right)$.

The reservoir layer is bounded above, below, and laterally by water-saturated shales that act as no-flow fluid boundaries. To solve for the streaming potential, additional layers are added laterally around the no-flow boundaries to a distance of $50 \mathrm{~m}$, and the domain is extended upward by $500 \mathrm{~m}$ (to the earth surface) and downward by $1400 \mathrm{~m}$ to a total depth of $2000 \mathrm{~m}$. Zero-gradient boundary conditions in the electric potential are enforced on the lateral and upper boundaries, simulating zero current flow, and a zero-potential boundary condition is enforced at the lower boundary to simulate the potential at "infinity." A simulation-based sensitivity analysis was used to demonstrate that the $50-\mathrm{m}$ lateral layers are wide enough to avoid the chosen boundary conditions affecting the potentials calculated within the reservoir.

In both models, a single well produces at a constant total fluid rate of $10,000 \mathrm{bbl} \mathrm{day}^{-1}$. In the vertical well model, a water-flood is initiated from one side of the domain $(x=0)$, and production continues until the water has reached the production well, located at $x=1000 \mathrm{~m}$ (Figure 4a). The well is open to flow over a single $100 \mathrm{~m}$ interval, from 500- to 600-m depth. In the horizontal well model, the oil-water contact lies $30 \mathrm{~m}$ below the top of the reservoir, so the lower $70 \mathrm{~m}$ of sandstone are saturated with water, which provides pressure support during production and moves upward toward the well when production is initiated. The well is located $10 \mathrm{~m}$ below the top of the reservoir and is open to flow over two 350-m sections, separated by $100 \mathrm{~m}$ (Figure 4b). Completion 1 is intersected by the high permeability layer, and completion 2 is entirely within the main part of the reservoir with lower vertical permeability. Water breakthrough is defined as the time at which water makes up $1 \%$ of the total fluid produced at any point along the well.

In each geometry, we also present results from heterogeneous reservoirs that have zones of contrasting permeability. In the vertical well geometry, model $\mathrm{V} 2$ has a narrow $(15 \mathrm{~m})$ anisotropic zone in the upper part of the reservoir, model V3 has a wide $(30 \mathrm{~m})$ anisotropic zone in the upper part of the reservoir, and model V4 has two narrow $(15 \mathrm{~m}$ ) anisotropic zones within the reservoir (Figure 5, Table 2). In each case the horizontal permeability of the contrasting region is increased to $k_{x}=1520 \mathrm{mD}$. The high permeability zones do not intersect the well but end $190 \mathrm{~m}$ away, so that it would not be possible to identify their presence from borehole logs. In the heterogeneous horizontal well models $\mathrm{H} 2-4$, a single channel running vertically through the reservoir has isotropic permeability $\mathbf{k}=1520 \mathrm{mD}$ (Figure 6, Table 2).

Irreducible water $\left(S_{w i}\right)$ and oil $\left(S_{n w i}\right)$ saturations are both equal to 0.2 . Corey-type relative permeabilities for the wetting (water) and nonwetting (oil) phases are given by (Anderson, 1987)

$$
k_{r w}=0.3 S_{m w}^{4}
$$

Figure 4. (a) The vertical well model, showing the reservoir intersected by a single well (black line), with water (pale) displacing oil (black). The well is located at $(x, y)=(250 \mathrm{~m}, 1000 \mathrm{~m})$ and production is uniform over the thickness of the reservoir (black line) with two producing sections (thick black lines). The well is located at $(x, z)=(0 \mathrm{~m},-510 \mathrm{~m})$. The larger surrounding box (semitransparent) is the domain for the electric problem extending up to the earth surface $(z=0 \mathrm{~m})$ and down to $z=-2000 \mathrm{~m}$ where the potential is set to zero. All dimensions in meters.

b)

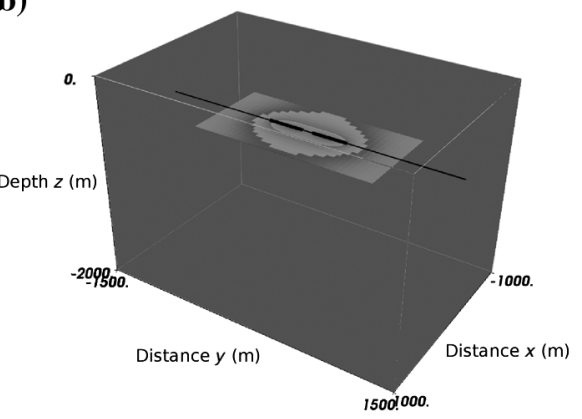

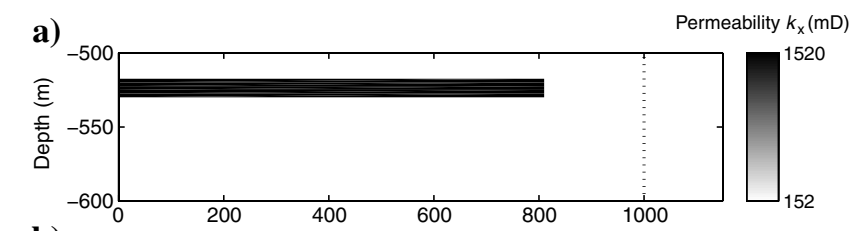

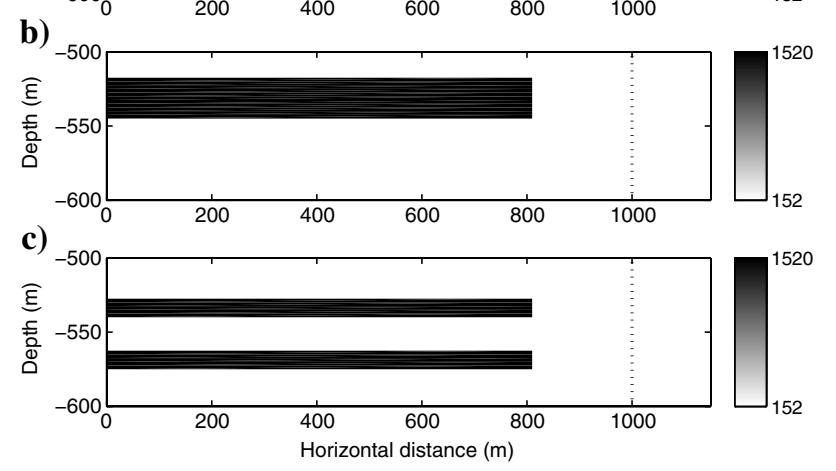

Figure 5. Cross sections of the heterogeneous models with the vertical well geometry showing horizontal permeability $k_{x}$. (a) Model V2 has a single, narrow high-permeability layer; (b) V3 has a single, wide high-permeability layer and (c) V4 has two narrow highpermeability layers. None of the high-permeability zones intersect the well, which is marked by a vertical dotted line. 


$$
k_{r n w}=0.8\left(1-S_{m w}\right)^{4}
$$

We note that while the endpoints 0.3 and 0.8 are typical for waterwet sandstones, varying them will directly affect the pressure gradient for a given production (flow) rate. Lower values will increase the required pressure gradient and therefore also the streaming potential, and vice versa. Capillary pressure is neglected (Dake, 1978; Shook et al., 1992) because the fluid displacement is dominated by viscous forces in the vertical-well model, and by viscous and gravity forces in the horizontal-well model. Four viscosity values for the displaced oil are considered, to investigate the effect of the waterfront saturation and the pressure gradient in the vicinity of the well on the measured streaming potentials. In the first instance, $\eta_{w}=\eta_{n w}=0.001 \mathrm{~Pa} \cdot \mathrm{s}$, with subsequent models having the oil phase viscosity multiplied by 2,4 and 8 .

The conductivity of the saturated rock is given by (Telford et al., 1990)

$$
\sigma_{f}=\phi^{1.8}\left(\sigma_{n w}+S_{w}^{n}\left[\sigma_{w}-\sigma_{n w}\right]\right),
$$

where $n$ is Archie's saturation exponent, hereafter equal to 1.65. This equation is applicable where the conductivity of the nonwetting phase is small compared to that of the wetting phase, and where surface conductivity is neglected. A more general equation for the conductivity of porous materials containing multiple fluid phases is given by Glover et al. (2000).
Table 2. Description of the four vertical-well models and four horizontal-well

\begin{tabular}{|c|c|c|}
\hline $\begin{array}{l}\text { Model } \\
\text { name }\end{array}$ & $\begin{array}{l}\text { Principle reservoir } \\
\text { permeability }\end{array}$ & Contrasting region \\
\hline V1 & $\mathbf{k}=152 \mathrm{mD}$ & None \\
\hline $\mathrm{V} 2$ & $\mathbf{k}=152 \mathrm{mD}$ & $k_{x}=1520 \mathrm{mD}$ at $z=-530--515 \mathrm{~m}$ \\
\hline V3 & $\mathbf{k}=152 \mathrm{mD}$ & $k_{x}=1520 \mathrm{mD}$ at $z=-545--515 \mathrm{~m}$ \\
\hline V4 & $\mathbf{k}=152 \mathrm{mD}$ & $\begin{array}{c}k_{x}=1520 \mathrm{mD} \text { at } z=-577.5--562.5 \mathrm{~m} \text { and } \\
z=-537.5--522.5 \mathrm{~m}\end{array}$ \\
\hline $\mathrm{H} 1$ & $\begin{array}{l}k_{x, y}=152 \mathrm{mD} \\
k_{-}=3 \mathrm{mD}\end{array}$ & None \\
\hline $\mathrm{H} 2$ & $\begin{array}{l}k_{x, y}=152 \mathrm{mD} \\
k_{7}=3 \mathrm{mD}\end{array}$ & 110 m-wide zone with $\mathbf{k}=152 \mathrm{mD}$ \\
\hline $\mathrm{H} 3$ & $\begin{array}{l}k_{x, y}=152 \mathrm{mD} \\
k_{z}=3 \mathrm{mD}\end{array}$ & 210 m-wide zone with $\mathbf{k}=152 \mathrm{mD}$ \\
\hline $\mathrm{H} 4$ & $\begin{aligned} k_{x, y} & =152 \mathrm{mD} \\
k_{z} & =3 \mathrm{mD}\end{aligned}$ & 310 m-wide zone with $\mathbf{k}=152 \mathrm{mD}$ \\
\hline
\end{tabular}
models used, which vary in their permeability structure.

\section{RESULTS}

We begin by discussing the effect of varying brine salinity and temperature on the streaming potentials predicted at the well. We then investigate the effect of using three different models for the behavior of the streaming-potential coupling coefficient at intermediate saturation. Finally, we consider heterogeneous reservoir models and look not only at the effect of the heterogeneity on the streaming potentials but also at the possibility of recognizing and responding to the nonuniform approach of water toward the well.

Potentials at the well are reported with respect to zero defined at infinity. In reality, a reference electrode must be positioned somewhere in the vicinity of the well, ideally at a location far from the moving fluids and with a stable or predictable background potential. The most sensible position from a practical point of view would be above the electrically conductive shale layer which bounds the reservoir. This layer shields the electrode from the streaming potentials generated in the reservoir, but the electrode is sufficiently deep that it is also shielded from surface electric noise. In the vertical-well model presented here, where the reservoir is situated at a depth of $500 \mathrm{~m}$ below the earth's surface, referencing the potential to an electrode positioned at the upper edge of the shale layer (i.e., at $400 \mathrm{~m}$ depth) reduces the magnitude of the measured potential by approximately $4 \%$ at breakthrough (Figure $7 \mathrm{a}$ ). In the horizontal-well model, at the same depth (i.e., at $400 \mathrm{~m}$ depth on the well tubing as it curves to the earth surface), the magnitude of the streaming potential is reduced by approximately $8 \%$ at breakthrough (Figure $7 b$ ).

\section{Effect of varying salinity and temperature}

Despite the variation with temperature of the four parameters which make up the streaming-potential coupling coefficient, the combined effect is small (Figure 2). The maximum streaming potential predicted at the well (Figure 8) in the homogeneous verticalwell model $\mathrm{V} 1$ at the point of water breakthrough reflects this behavior. Potential increases by about $10 \%$ between $25^{\circ} \mathrm{C}$ and $75^{\circ} \mathrm{C}$ at low salinity, and decreases by a similar amount over the same range at salinities close to or above the salinity of sea water. Brine salinity is the dominant factor in determining the magnitude of the signal predicted downhole. 
Given the relative insignificance of temperature in determining either the magnitude of the streaming-potential coupling coefficient or the predicted potentials in the vertical-well models, we now neglect the effect of temperature for the horizontal-well modeling. In the homogeneous horizontal-well model H1, the maximum streaming potential at breakthrough again decreases with increasing salinity (Figure 9$)$. At sea water salinity $\left(0.6 \mathrm{~mol} \cdot \mathrm{L}^{-1}\right)$ this value is $3.5 \mathrm{mV}$, and at $5.0 \mathrm{~mol} \cdot \mathrm{L}^{-1}$ approximately $0.16 \mathrm{mV}$.

\section{Effect of varying the relative coupling coefficient and viscosity ratio}

Using the homogeneous vertical-well model V1, four cases with varying viscosity ratios between the oil and brine are considered. The oil viscosity $\left(\eta_{n w}\right)$ is initially equal to the brine viscosity $\left(\eta_{w}=0.001 \mathrm{~Pa} \cdot \mathrm{s}\right)$ and is then multiplied by 2,4 , and 8 for the other cases. The effect of increasing the oil viscosity is to smear out the water front as the brine displaces the oil at a lower saturation fraction (Figure 10), and the immediate consequence of this is to cause water breakthrough at the well to occur earlier.

The viscosity-dependent rarefaction of the water front described above is important when it comes to comparing the streaming potentials predicted by each of the models for the relative coupling coefficient. At intermediate saturations, the Jackson model gives the largest values for the coupling coefficient and the Revil model the smallest values (Figure 3). The linear relationship of the Guichet model lies in between. Comparing the streaming potentials along a
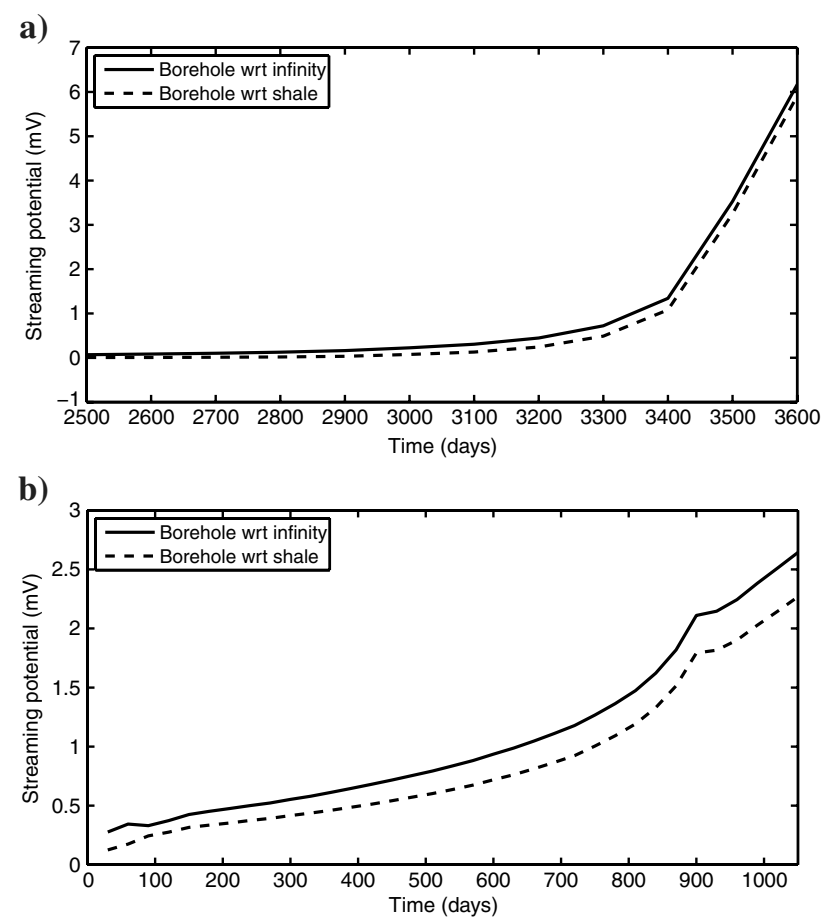

Figure 7. (a) Streaming potential at the well with respect to an electrode at infinity and with respect to a reference electrode at the top of the shale layer in the vertical-well model V1. (b) Streaming potential at the well with respect to an electrode at infinity and with respect to a reference electrode at the top of the shale layer in the horizontal-well model H1. Water breakthrough occurs at the right edge of each figure.

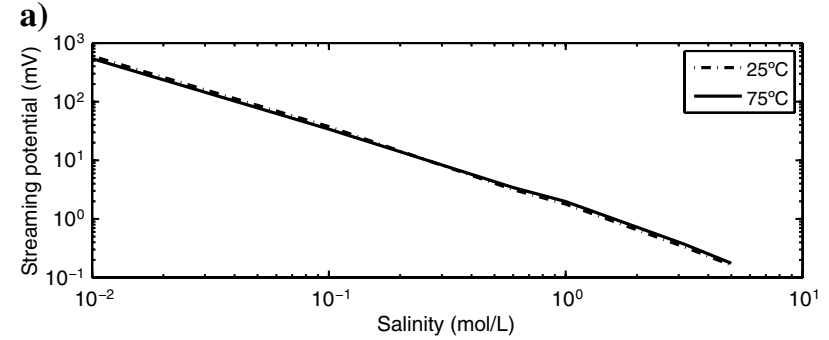

b)

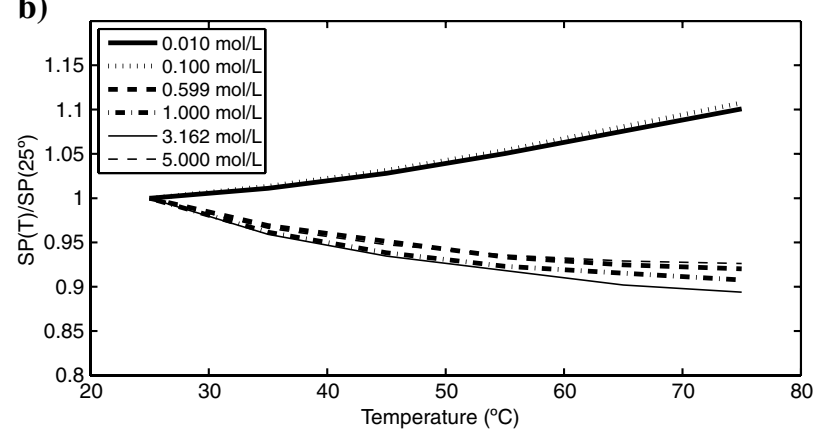

Figure 8. (a) Streaming potential predicted at the well (depth $550 \mathrm{~m}$ ) at breakthrough in the vertical-well model V1, plotted against salinity for temperatures of $25^{\circ} \mathrm{C}$ and $75^{\circ} \mathrm{C}$. (b) Streaming potential predicted at the well (depth $550 \mathrm{~m}$ ) relative to its value at $25^{\circ} \mathrm{C}$ in the vertical-well model $\mathrm{V} 1$, plotted against temperature for a range of salinities. The behavior mirrors that of $C$ (Figure 2), increasing with temperature up to salinities of $0.1 \mathrm{~mol} \cdot \mathrm{L}^{-1}$, but decreasing with increasing temperature at higher salinities. Values $(\mathrm{mV})$ at $25^{\circ} \mathrm{C}: 543.2\left(0.01 \mathrm{~mol} \cdot \mathrm{L}^{-1}\right), 33.9\left(0.1 \mathrm{~mol} \cdot \mathrm{L}^{-1}\right), 3.44$ $\left(0.6 \mathrm{~mol} \cdot \mathrm{L}^{-1}\right), \quad 1.98\left(1 \mathrm{~mol} \cdot \mathrm{L}^{-1}\right), \quad 0.373\left(3.16 \mathrm{~mol} \cdot \mathrm{L}^{-1}\right)$, $0.176\left(5 \mathrm{~mol} \cdot \mathrm{L}^{-1}\right)$.

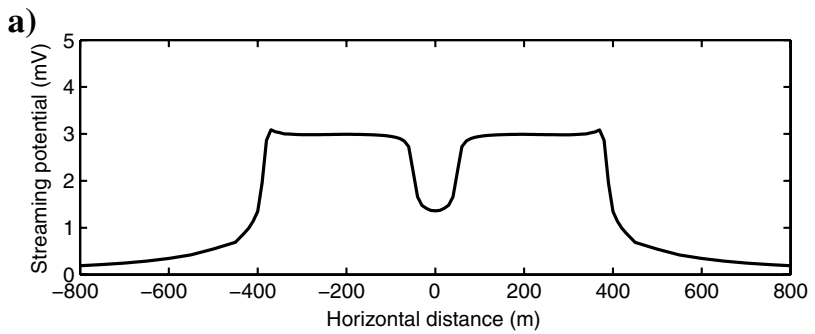

b)

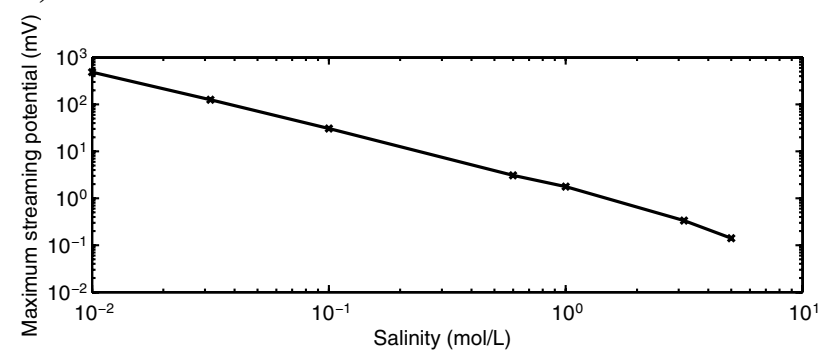

Figure 9. (a) The streaming potential predicted along the well for the horizontal-well model $\mathrm{H} 1 \mathrm{l}$ using brine with seawater salinity $\left(0.6 \mathrm{~mol} \cdot \mathrm{L}^{-1}\right)$. The shape of the curve reflects the fact that the water is approaching the two separate completions along the well. (b) The maximum streaming potential at breakthrough versus salinity, showing the expected decrease in values with increasing salinity. 
line through the water front and through the well after 2700 days (Figure 11) we see that, in terms of magnitude, the results follow the same order. Two other features are noticeable. First, that the magnitude of the signals increases as the viscosity ratio increases. This is due to a combination of an increase in the pressure gradient (as the front is nearer the well and the relative permeability to brine is lower than that to oil) and the maximum brine saturation (and therefore the bulk conductivity) at the front being lower. Second, the difference between the predictions of the three models also increases as the viscosity ratio increases. For the equal viscosity case the difference between the predictions of the Revil and Jackson models is a factor of 2.5 , while when the viscosity ratio is eight the difference is a factor of 4.8 .

The predictions of streaming potential at the midpoint of the production well show a similar trend (Figure 12). Both the potential at breakthrough and the difference between the predictions of the three models increase as the viscosity ratio increases. The behavior of the relative coupling coefficient then, is important in governing the magnitude of the measured streaming potential, and this influence becomes greater as the water front becomes less well defined.

\section{Effect of reservoir heterogeneity}

Vertical well

The inclusion of regions of high permeability $\left(k_{x}=1520 \mathrm{mD}\right)$ in models V2, 3, and 4 (Figure 5, Table 2) causes the water front to flow unevenly toward the well. It would be impossible to anticipate this uneven flow by analyzing borehole logs, because the regions of high permeability do not intersect the well but end $190 \mathrm{~m}$ away in the direction of the approaching water. Using measurements of streaming potential during production, however, it would be possible to ascertain that the water front was not flowing uniformly. Where there is a single high permeability layer in the top half of
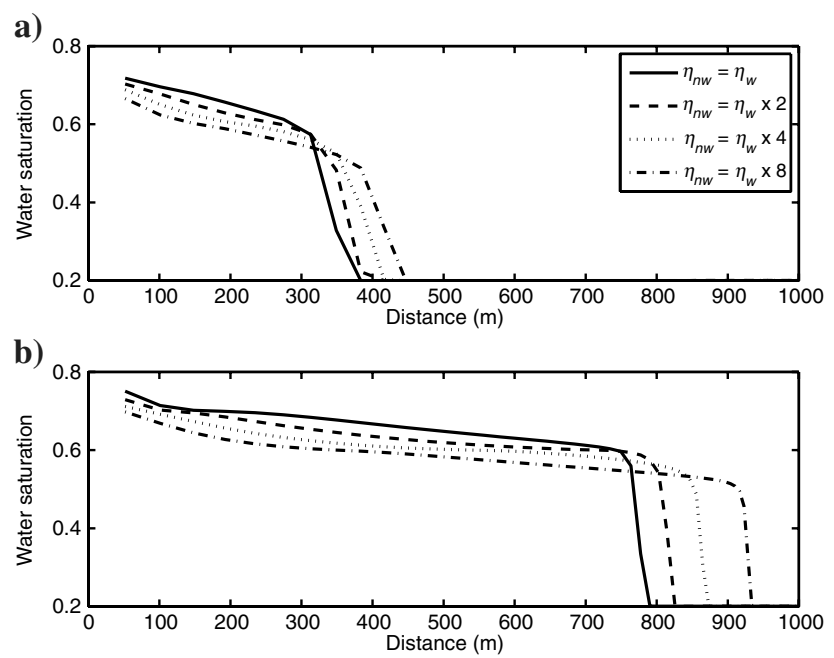

Figure 10. Line sections parallel to the $y$-axis (see Figure 4a) through the approaching water front at a depth of $550 \mathrm{~m}$ in the vertical-well model V1, showing water saturation and the effect of increased oil viscosity after (a) 1000 days production, and (b) 2700 days. As oil viscosity increases, the front becomes less well defined and proceeds more quickly towards the well (at $1000 \mathrm{~m}$ ). the reservoir, the peak of the streaming-potential curve along the well clearly shifts upward (Figures 13a, and h). With two highpermeability layers the heterogeneity is not immediately so obvious (Figures 13i, and 1), and it is only by comparing the potential curves

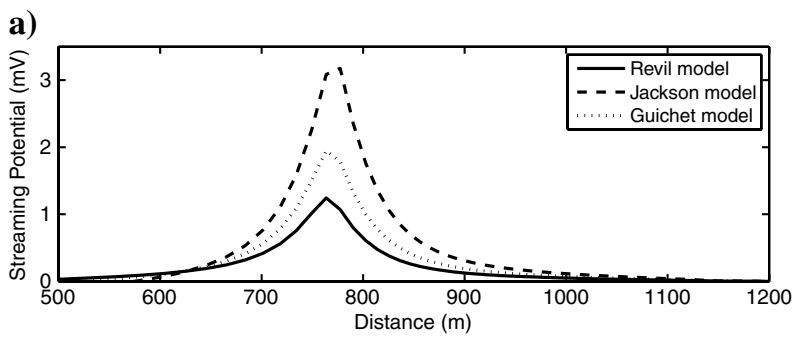

b)

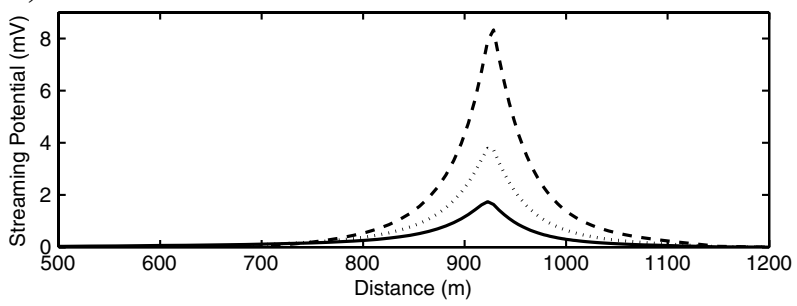

Figure 11. Line sections parallel to the $y$-axis (see Figure 4a) through the approaching water front at a depth of $550 \mathrm{~m}$, showing streaming potential after 2700 days of production in the homogeneous vertical model V1 for the three proposed models of relative coupling coefficient. (a) Equal viscosities $\eta_{n w}=\eta_{w}$ (b) $\eta_{n w}=8 \times \eta_{w}$. The difference in predictions between the three models increases significantly as the viscosity ratio increases, from a factor of 2.5 in (a) to 4.8 in (b).

a)

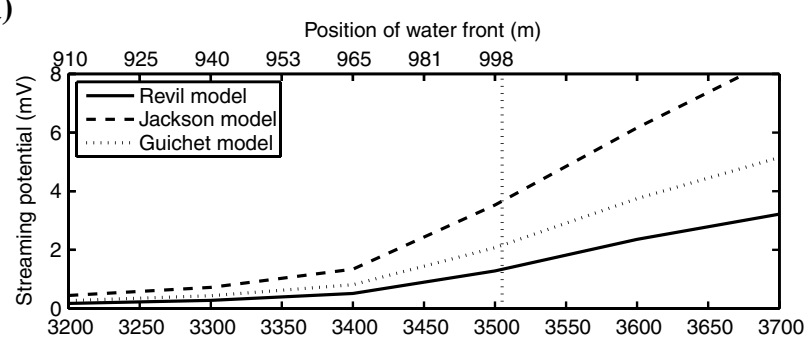

b)

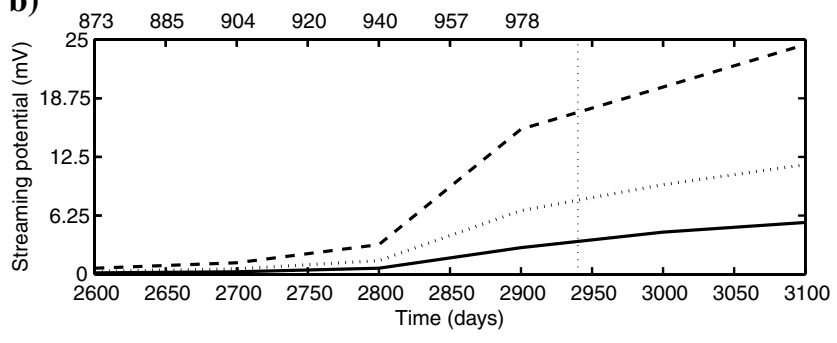

Figure 12. Streaming potential predicted at the well at a depth of $550 \mathrm{~m}$ for the three models of relative coupling coefficient: (a) $\eta_{n w}=\eta_{w}$ (b) $\eta_{n w}=8 \times \eta_{w}$. The time of water breakthrough is marked by the vertical dotted line. As well as the magnitude of the streaming potentials increasing as the viscosity ratio increases, the difference between the predictions of the three models for the relative coupling coefficient increases. 
with the equivalent curves from the homogeneous model V1 that some insight can be gained (Figure 14). As the water arrives at the well in model V4 the central peak of the potential curve is much flatter, reflecting the fact that the highest water saturation is toward the top and bottom of the reservoir. Such a distinction would perhaps only become apparent through modeling or inversion of the streaming potentials during production. In all of the heterogeneous cases the potentials are initially smaller for the same water front distance. We attribute this to the smaller effective area of the water front, and the consequent reduction in the surface area of the current source.

\section{Horizontal well}

Models H2, H3, and H4 (Figure 6, Table 2) differ in the width of the high-permeability zone which runs vertically through the reservoir, from the underlying aquifer to the well. The streaming potentials predicted at the well (Figure 15) mirror the saturation distribution of brine in the reservoir beneath. Where the invading brine has the salinity of sea water $\left(0.6 \mathrm{~mol} \cdot \mathrm{L}^{-1}\right)$, the streaming a)

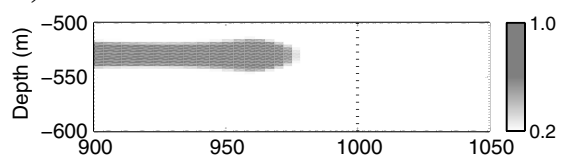

c)

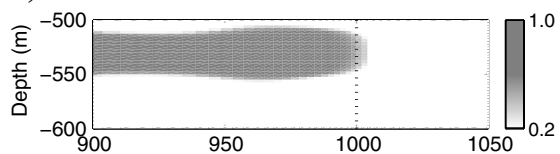

e)

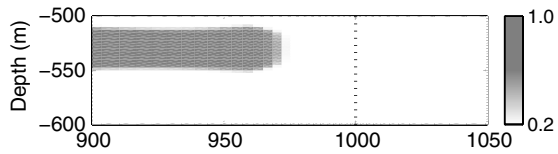

g)

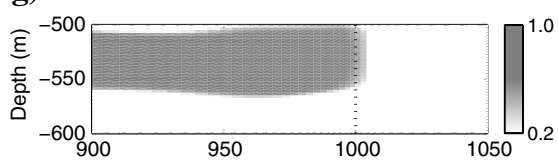

i)

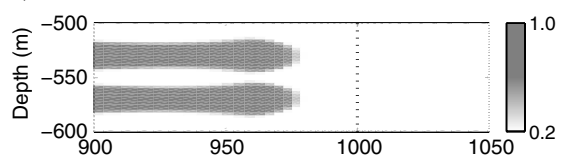

k)

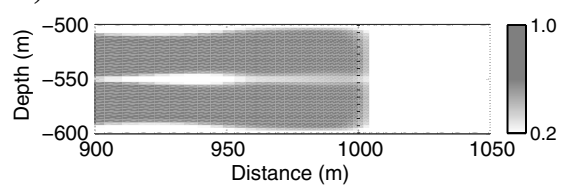

b)

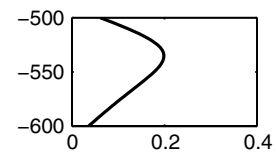

d)

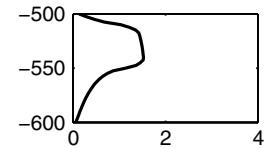

f)

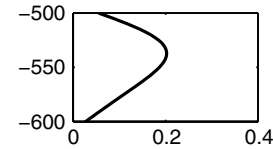

h)

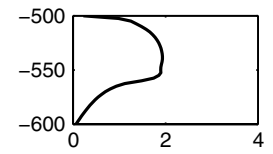

j)

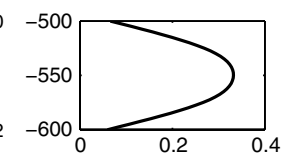

l)

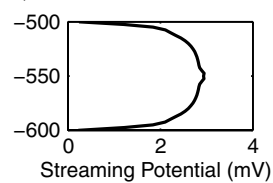

Figure 13. Vertical cross sections showing saturation distribution and predicted streaming potentials along the well for vertical-well models V2 (a-d), V3 (e-h), and V4 (i-l), where the water front is $25 \mathrm{~m}$ from the well and at the well. The well position is marked by a dotted line at $1000 \mathrm{~m}$. potential measured at the well is approximately $0.6-0.8 \mathrm{mV}$ when the water is halfway to the well, and approximately $1-1.2 \mathrm{mV}$ at breakthrough.

The shape of the potentials along the well reflect the shape of the approaching water front so closely that it would be straightforward to turn the streaming-potential measurements into a control response by linking an increasing streaming-potential measurement to locally advancing water. In this case, the strategy would involve reducing or terminating production in completion 1 and continuing in completion 2 only. In this way a greater volume of oil could be brought to surface before any unwanted water, and the overall viable recovery possible from the reservoir increased. However, even if there were more completions and if multiple permeability structures overlapped them, with sufficient electrodes and therefore good spatial resolution in the electric measurements, a similarly simple control strategy could be implemented.

This is the first time that predictions of streaming potential in a heterogeneous reservoir with multiple completions have been made, and it is interesting to note that even after water is being produced in one completed zone, the streaming-potential measurements made on the other completed section are still able to distinguish the approaching water and are not dominated by signals from the first completion. In reality, it is likely that the acceptable threshold for water production would be considerably above $1 \%$ and so it is important that water flowing at one part of the well does not make it impossible to monitor approaching water in other parts.

\section{DISCUSSION}

The results presented here give an insight into the behavior of streaming potentials in reservoir conditions, and we have shown how they may be affected by the production regime for a well, and also how the potentials may be used to inform and improve that regime. The practical question remains, however: when will this method work? This question encompasses reservoir geology, fluid composition, well geometry, production strategy, and
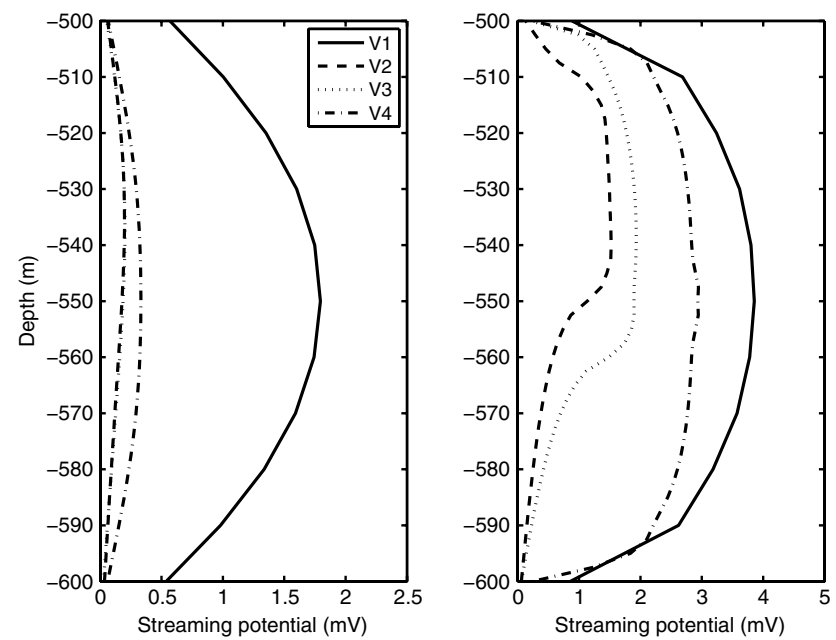

Figure 14. A comparison of the predicted streaming potentials along the well for the four vertical-well models when (a) the front is approximately $25 \mathrm{~m}$ away (models $\mathrm{V} 3$ and V4 almost coincident), and (b) at breakthrough. 
numerous other factors both within and outside the control of a reservoir engineer, but comes down to the maximum magnitude of the streaming potential that can be expected in any one particular reservoir environment. The method of using streaming potentials to

a)

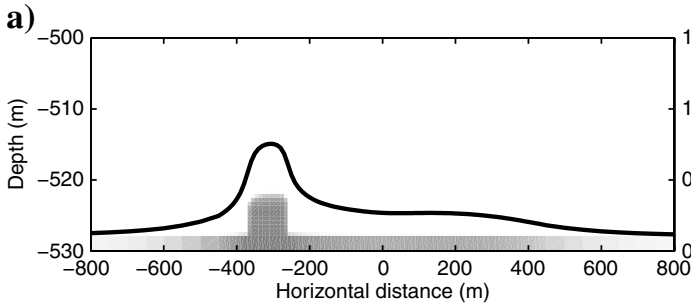

Saturation

b)

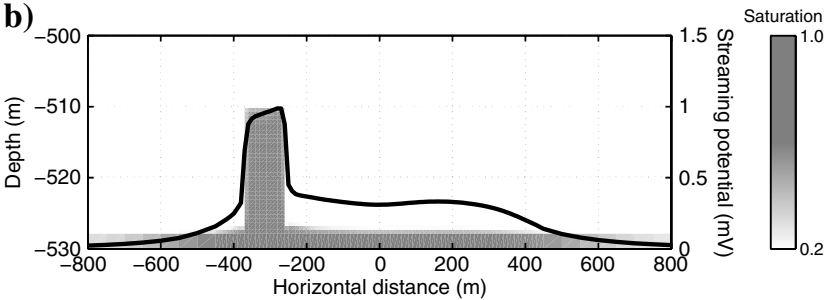

c)

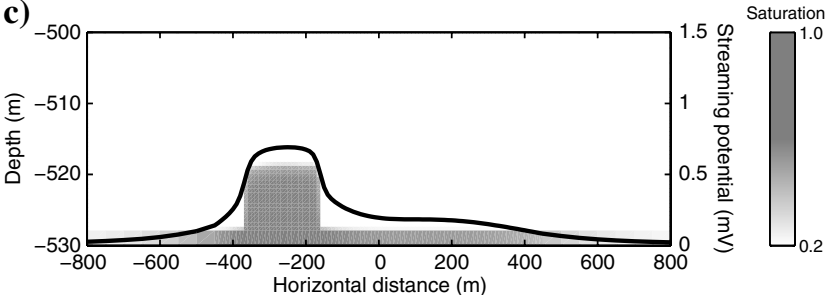

d)

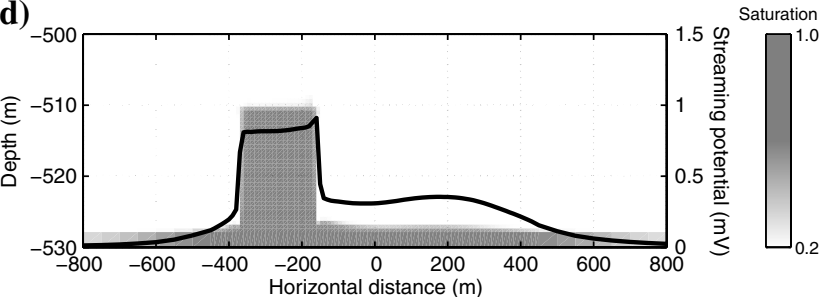

e)

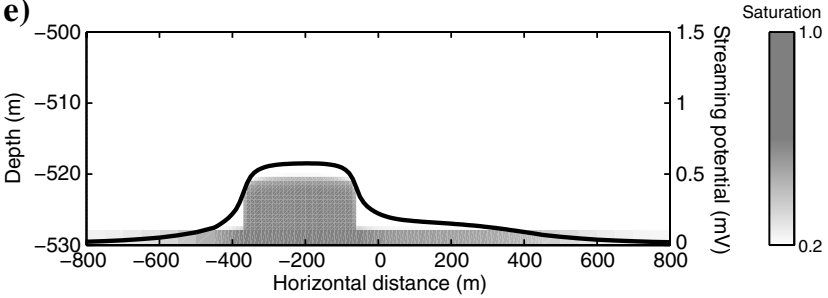

f)

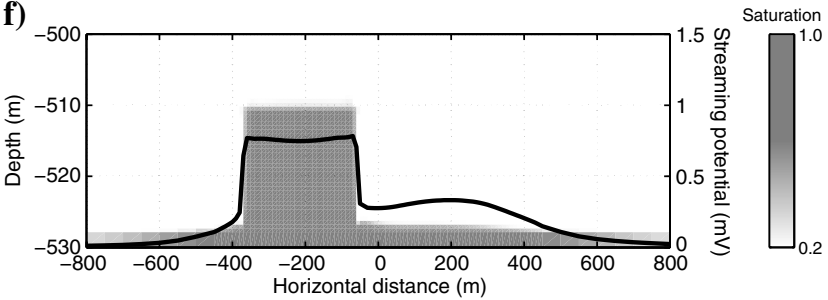

Figure 15. Brine saturation and streaming-potential predictions for the horizontal well models. (a and b) Model H2 after 60 and 150 days, respectively. (c and d) Model H3 after 60 and 150 days, respectively. (e and f) Model H4 after 60 and 150 days, respectively. monitor the approach of water toward a well depends on the ability to detect those potentials while the water is still far enough away that a meaningful response strategy can be implemented. If this is possible, then the potentials will certainly be measurable once the water has arrived at the well. The expected level of background electric noise, then, is crucial in determining whether a set of reservoir parameters will be suitable for streaming-potential monitoring.

Bryant et al. (2002) monitor streaming potentials downhole with electrodes mounted on the outside of an insulated steel casing. The electrodes were cemented in place to give them both an electric contact with the reservoir fluids, and also a relatively stable environment to minimize the common problems of potential drift and electrode polarization. The noise levels recorded in these experiments was of the order of $0.1 \mathrm{mV}$, and although this will certainly vary from one reservoir to another, we have chosen here to use $0.1 \mathrm{mV}$ as the minimum value of streaming potential measurable downhole. This value can therefore be used to evaluate the viability of the streaming-potential method in the reservoirs discussed in this paper, under the full range of combinations of fluid and well properties. Note that we have assumed that the steel casing is fully insulated from the reservoir fluids, and does not form part of the resistivity structure of the modeled system.

In the vertical well with a constant production rate of $10,000 \mathrm{bbl} \mathrm{day}^{-1}$, we find that the predicted streaming potential at breakthrough is above $0.1 \mathrm{mV}$ for all combinations of salinity, temperature, viscosity ratio, and for each relative coupling coefficient model, except for the Revil model with viscosity ratios of one or two, where the salinity must be below approximately $3.5-4 \mathrm{~mol} \cdot \mathrm{L}^{-1}$. Alternatively, for a fixed temperature of $55^{\circ} \mathrm{C}$ (Figure 16), we find that where viscosities are equal, with brine salinity equal to $0.6 \mathrm{~mol} \cdot \mathrm{L}^{-1}$ the minimum production rate for a)

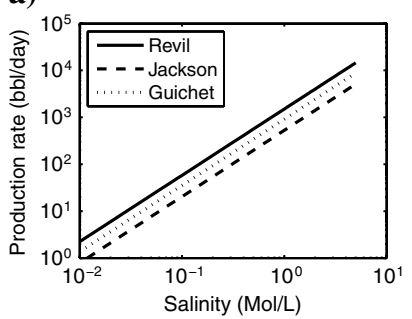

c)

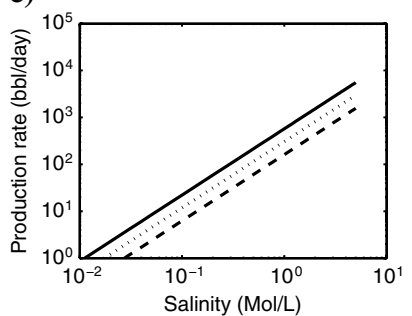

b)

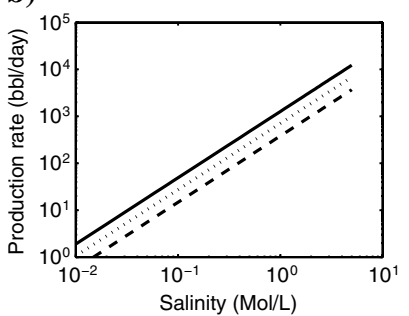

d)

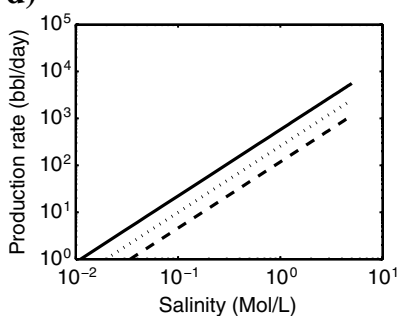

Figure 16. Limit of viability for the vertical-well model V1 with a temperature of $55^{\circ} \mathrm{C}$ for oil-brine viscosities ratios of (a) one (b) two (c) four and (d) eight; production rates above the marked line give potentials larger than $0.1 \mathrm{mV}$ at breakthrough. The Jackson model always allows a lower production rate, and the difference between this and the other models increases as the viscosity ratio increases. 
the Revil model is $700 \mathrm{bblday}^{-1}$, for the Guichet model $450 \mathrm{bbl} \mathrm{day}^{-1}$ and for the Jackson model $300 \mathrm{bbl} \mathrm{day}^{-1}$. With an oil-brine viscosity ratio of eight the minimum rates are $300 \mathrm{bbl} \mathrm{day}^{-1}$ for Revil, $150 \mathrm{bblday}{ }^{-1}$ for Guichet, and $60 \mathrm{bbl} \mathrm{day}^{-1}$ for Jackson. This numerical model will allow similar analyses on the horizontal well or indeed on any other reservoir model, providing an outline of feasibility for the use of streaming potentials downhole.

We have assumed a $\mathrm{pH}$ of seven for the system throughout this work. If we consider that the $\mathrm{pH}$ of a reservoir may be slightly higher or lower than this, then we must consider the effect of this change on the measured potentials. Leroy et al. (2008) show that at $\mathrm{pH} 6$ the zeta potential is more than half of its value at $\mathrm{pH} 8$ in the salinity range above $1 \times 10^{-2} \mathrm{~mol} \cdot \mathrm{L}^{-1}$. Because throughout most of the temperature and salinity range discussed above, the predicted streaming potentials are many times larger than the expected noise, alterations in $\mathrm{pH}$ are therefore not expected to have an important effect on the viability of the method.

\section{CONCLUSIONS}

High salinities, high temperatures, and the nature of the saturation-dependent coupling coefficient are among several factors that have previously been seen as obstacles to the viability of using streaming-potential methods downhole during hydrocarbon recovery. We show that, across the salinity range, temperature has a small effect on the magnitude of the streaming-potential coupling coefficient, and therefore also on the predicted downhole streaming potentials. Using a new model of the zeta potential at high salinity, we show that the magnitude of streaming potentials predicted downhole remains above the expected level of background electric noise, even at salinities well above that of seawater. We compare vertical and horizontal well geometries, and find that in both cases, but particularly with a horizontal well, where the need for such monitoring technology may be greatest, the streaming-potential method is clearly able to distinguish and locate water advancing toward the well. We explore three models for the behavior of the streaming-potential coupling coefficient at intermediate saturation. All three models give measurable signals across a wide range of geophysical properties and production scenarios, both in the vertical- and horizontal-well geometries, and that using the model that is closest to the available experimental data, we measure signals larger than previously predicted, especially where the oil viscosity is higher than that of the displacing water. We also find that, assuming electric isolation of the electrodes from the steel casing, the upper part of the borehole is well shielded from the electric potentials in the reservoir by the surrounding conductive shale-like layers. Such a location may be ideal for positioning a reference electrode against which to make the streaming-potential measurements in the reservoir. Removing these obstacles is a significant step forward in the development of the downhole monitoring method.

\section{ACKNOWLEDGMENTS}

The authors gratefully acknowledge the support of Shell International Exploration and Production B.V. We would also like to thank André Revil and the anonymous reviewers for their assistance in preparing this work for publication.

\section{APPENDIX A}

\section{TEMPERATURE AND SALINITY DEPENDENCE OF ZETA POTENTIAL, BRINE PERMITTIVITY, VISCOSITY, AND CONDUCTIVITY}

\section{Zeta potential}

Revil et al. (1999) provide a model for the behavior of the zeta potential

$$
\begin{aligned}
\zeta= & \frac{2 k_{b} T_{K}}{3 e} \ln \left[\frac{\sqrt{8.10^{3} \epsilon_{w} k_{b} T_{K} \mathcal{N}}}{2 e \Gamma_{S}^{0} K_{(-)}}\left(\frac{C_{a}+C_{f}+10^{-p H}}{\sqrt{I_{f}}}\right)\right. \\
& \left.\times\left(10^{-p H}+K_{M e} C_{f}\right)\right],
\end{aligned}
$$

which assumes that the Stern plane (the location of partially mobile ions (Ishido and Mizutani, 1981)) and shear plane are coincident. Here, $k_{b}$ is Boltzmann's constant $\left(1.381 \times 10^{-23} \mathrm{JK}^{-1}\right), T_{K}$ is the temperature in $\mathrm{K}, e$ is the elementary charge $\left(1.602 \times 10^{-19} \mathrm{C}\right), \mathcal{N}$ is Avogadro's constant $\left(6.0221415 \times 10^{23}\right), K_{M e}$ is the binding constant for the cation reaction, $\Gamma_{S}^{0}$ is the surface site density $\left(\mathrm{m}^{-2}\right)$, $K_{(-)}$is the dissociation constant for the surface mineral reactions, $C_{a}$ is the concentration of acid in the free electrolyte $\left(\mathrm{mol} \cdot \mathrm{L}^{-1}\right)$ and $I_{f}$ is the ionic strength of the brine. We note here that equation A-1 is an analytical solution to more general equations given by Revil and Glover (1997), and that a more accurate solution may be found by solving the full equations numerically.

Typical $\mathrm{pH}$ values for reservoirs are in the range 6-7.5 (Barth, 1991). The $\mathrm{pH}$ of seawater, which will most usually be the water injected for waterflooding, lies in the range 7.5-8.3 (Orr et al., 2005; Seidel et al., 2008). The relevant $\mathrm{pH}$ for our discussion is therefore likely to fall in the range 6.5-8. For salinities above

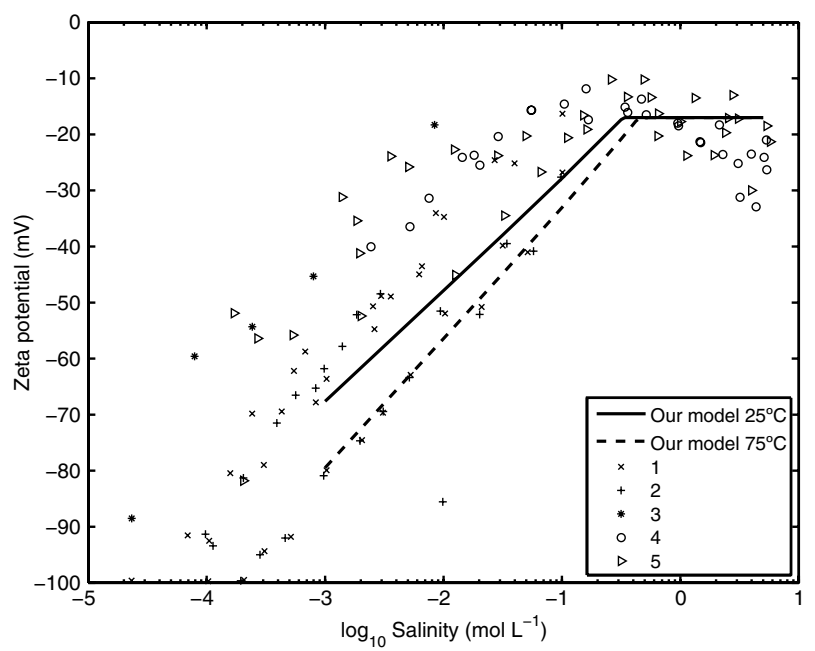

Figure A-1. Zeta potential versus salinity, showing our model (equation A-2 for temperatures of $25^{\circ} \mathrm{C}$ and $75^{\circ} \mathrm{C}$, and data from the literature with $\mathrm{NaCl}$ brine and a variety of materials: (1) silica (Gaudin and Fuerstenau, 1955; Li and de Bruyn, 1966; Kirby and Hasselbrink, 2004), (2) quartz (Pride and Morgan, 1991), (3) glass beads (Bolève et al., 2007), (4) St Bees sandstone (Jaafar et al., 2009), (5) a variety of sandstones and brine compositions (Vinogradov et al., 2010). Our model is limited at the low salinity end by our assumption of zero surface conductivity. 
$0.01 \mathrm{~mol} \cdot \mathrm{L}^{-1}$ the zeta potential is expected to vary by a factor of less than two between pH 6 and 8 (Ishido and Mizutani, 1981; Leroy et al., 2008) (increasing in magnitude with $\mathrm{pH}$ ), with the dependence decreasing as salinity increases. Although we will reconsider this in our later discussion, we will assume hereafter that the $\mathrm{pH}$ of the system is 7 .

The model given by equation A-1 is applicable up to salinities of approximately $0.01 \mathrm{~mol} \cdot \mathrm{L}^{-1}$ (Revil et al., 1999). At higher salinity, it is necessary to consider the physical sizes of the ions present in the electrolyte, and the packing density that can be achieved on a mineral surface. In laboratory experiments, Jaafar et al. (2009) have measured streaming potentials up to and beyond seawater salinity and have shown that, above approximately $0.3 \mathrm{~mol} \cdot \mathrm{L}^{-1}$, the magnitude of zeta potential no longer decreases with salinity (Figure A-1). Vinogradov et al. (2010) suggest that this occurs because the maximum packing of counterions within the diffuse layer has been reached. As the salinity increases beyond this point, the counterion density within the double layer remains constant, and so the zeta potential also remains constant. At $23^{\circ} \mathrm{C}$ this limit of zeta potential was found to be approximately $-17 \mathrm{mV}$, and we assume that the physical size of ions is expected to be only weakly temperature-dependent, and so the same value may be used as a limit at all temperatures. The exact point at which the zeta potential reaches $-17 \mathrm{mV}$ is salinity and temperature dependent, but we assume also that the transition between the two regimes is smooth.

We assume that the contribution from the acid is negligible compared to that from the salt, and that $C_{f}=I_{f}$ (Revil et al., 1999). Our model for zeta potential, therefore, becomes

$$
\begin{aligned}
\zeta= & \min \left(\frac { 2 k _ { b } T _ { K } } { 3 e } \operatorname { l n } \left[\frac{\sqrt{8.10^{3} \epsilon_{w} k_{b} T_{K} \mathcal{N}}}{2 e \Gamma_{S}^{0} K_{(-)}}\left(\frac{C_{f}+10^{-p H}}{\sqrt{C_{f}}}\right)\right.\right. \\
& \left.\left.\times\left(10^{-p H}+K_{M e} C_{f}\right)\right],-0.017\right) .
\end{aligned}
$$

We use $K_{M e}=10^{-7.5}$, typical of the values reported by Kosmulski (1996) for silica and $\mathrm{Na}^{+}$(see also references in Revil et al. (1999)). The values we have chosen to use for $K_{(-)}$and $\Gamma_{S}^{0}$ of $10^{-7.2}$ and 1.01 sites $\mathrm{nm}^{-2}$, respectively, are the best fit within the expected ranges to the available experimental data (Figure A-1). The value for $\Gamma_{S}^{0}$ is, however, lower than those reported by Revil et al. (1999), in some cases by almost one order of magnitude. Increasing this value would directly increase $\zeta$ and therefore also the coupling coefficient.

\section{Brine permittivity}

Equations for calculating the relative permittivity $\epsilon_{r}$ of brine at a given temperature $T$ and normality $N$ are given in Stogryn (1971),

$$
\epsilon_{r}(T, N)=\epsilon_{r}(T, 0) a(N),
$$

where (Malmberg and Maryott, 1956)

$$
\begin{aligned}
\epsilon_{r}(T, 0)= & 87.74-0.40008 T+9.398 \times 10^{-4} T^{2} \\
+ & 1.41 \times 10^{-6} T^{3}, \\
a(N)= & 1.0-0.2551 N+5.151 \times 10^{-2} N^{2} \\
& -6.889 \times 10^{-3} N^{3},
\end{aligned}
$$

and $N$ is the normality of the solution and is related to the salinity $\hat{C}_{f}$ (in parts per thousand) by

$$
N=\hat{C}_{f}\left(1.707 \times 10^{-2}+1.205 \times 10^{-5} \hat{C}_{f}+4.058 \times 10^{-9} \hat{C}_{f}^{2}\right) .
$$

The brine permittivity $\epsilon$ is then given by multiplying the relative permittivity by the vacuum permittivity $\epsilon_{0} \quad(=8.854187 \times$ $\left.10^{-12} \mathrm{~F} / \mathrm{m}\right)$

$$
\epsilon=\epsilon_{r} \epsilon_{0}
$$

Although only validated up to $40^{\circ} \mathrm{C}$, when extrapolated to $75^{\circ} \mathrm{C}$ for the zero salinity case, this model varies less than $2.5 \%$ from the experimental values given by Uematsu and Franck (1980). The applicable salinity range is $0 \leq C_{f} \leq 2.7 \mathrm{~mol} \cdot \mathrm{L}^{-1}$. Because we are not aware of any description of permittivity at salinities higher than that of seawater in conjunction with temperature, at higher salinities the curve of permittivity against salinity has been extrapolated, first by fitting the values given by the model from Stogryn (1971) against salinity using an exponential relation of the form $\epsilon=$ $A \times 0.766^{C_{f}}\left(\mathrm{R}^{2}>0.999\right.$ for the fit to salinities between 0.001 and $1.0 \mathrm{~mol} \cdot \mathrm{L}^{-1}$ ), and second by fitting the values of $A$ obtained across our salinity range; $A$ is temperature dependent and given by

$$
A=7.713 \times 10^{-10} \times 0.9958^{T} .
$$

The brine permittivity therefore decreases both with increasing salinity and with increasing temperature. We note here that experimental work by Hilland (1997) has suggested that the effect of salinity on permittivity may be weaker than that described above, with values roughly $7 \%$ larger at seawater salinity at $20^{\circ} \mathrm{C}$. This would increase the value of $C$ and therefore lead to larger streaming potentials.

\section{Brine viscosity}

The behavior of brine viscosity (in $\mathrm{Pa} \cdot \mathrm{s}$ ) across our range of interest is described by Kestin et al. (1978),

$$
\eta\left(T, C_{f}\right)=\eta(T, 0) \times \eta_{r}\left(T, C_{f}\right),
$$

where

$$
\begin{aligned}
\log _{10}\left(\frac{\eta(T, 0)}{\eta(20,0)}\right)= & \frac{1}{(96+T)}\left[( 2 0 - T ) \left(1.2378-1.303 \times 10^{-3}\right.\right. \\
& \times(20-T)+3.06 \times 10^{-6}(20-T)^{2} \\
& \left.\left.+2.55 \times 10^{-8}(20-T)^{3}\right)\right]
\end{aligned}
$$

and

$$
\eta(20,0)=0.001002
$$

The relative viscosity as a function of temperature at a given salinity $C_{f}$ is given by

$$
\log _{10}\left(\eta_{r}\left(T, C_{f}\right)\right)=A\left(C_{f}\right)+B\left(C_{f}\right) \log _{10}\left[\frac{\eta(T, 0)}{\eta(20,0)}\right],
$$


where

$$
\begin{aligned}
A\left(C_{f}\right)= & 3.3324 \times 10^{-2} C_{f}+3.624 \times 10^{-3} C_{f}^{2} \\
& -1.879 \times 10^{-4} C_{f}^{3},
\end{aligned}
$$

and

$$
\begin{aligned}
B\left(C_{f}\right)= & -3.96 \times 10^{-2} C_{f}+1.02 \times 10^{-2} C_{f}^{2} \\
& -7.02 \times 10^{-4} C_{f}^{3} .
\end{aligned}
$$

The effect of salinity is negligible up to $1 \mathrm{~mol} \mathrm{~L}^{-1}$, but increased temperature dramatically reduces the viscosity across the temperature range.

\section{Brine conductivity}

Brine conductivity (in $\mathrm{S} \mathrm{m}^{-1}$ ) is calculated from temperature in the range $20^{\circ} \mathrm{C}-200^{\circ} \mathrm{C}$ and salinity in the range $0.001-4.7 \mathrm{~mol} \mathrm{~L}^{-1}$ using the equation given by Sen and Goode (1992),

$$
\begin{aligned}
\sigma_{w}= & \left(5.6+0.27 T-1.5 \times 10^{-4} T^{2}\right) C_{f} \\
& -\frac{2.36+0.099 T}{1.0+0.214 C_{f}^{1 / 2}} C_{f}^{3 / 2} .
\end{aligned}
$$

Conductivity increases with both temperature and salinity.

\section{REFERENCES}

Addiego-Guevara, E. A., M. D. Jackson, and M. A. Giddens, 2008, Insurance value of intelligent well technology against reservoir uncertainty: SPE IOR Symposium.

Allègre, V., L. Jouniaux, F. Lehmann, and P. Sailhac, 2010, Streaming potential dependence on water-content in Fontainebleau sand: Geophysical Journal International, 182, 1248-1266, doi: 10.1111/j.1365-246X.2010 .04716.x.

Anderson, W. G., 1987, Wettability literature survey - Part 5: The effects of wettability on relative permeability: Journal of Petroleum Technology, 39, $1453-1468$.

Aziz, K., and A. Settari, 1979, Petroleum reservoir simulation: Elsevier Applied Science Publishers.

Barth, T., 1991, Organic-acids and inorganic-ions in waters from petroleum reservoirs, Norwegian continental-shelf - A multivariate statisticalanalysis and comparison with American reservoir formation waters: Applied geochemistry : Journal of the International Association of Geochemistry and Cosmochemistry, 6, 1-15, doi: 10.1016/0883-2927(91) 90059-X

Bolève, A., A. Crespy, A. Revil, F. Janod, and J. L. Mattiuzzo, 2007, Streaming potentials of granular media: Influence of the Dukhin and Reynolds numbers: Journal of Geophysical Research Solid Earth: JGR, 112, B08204, doi: 10.1029/2006JB004673.

Bryant, I. D., M. Y. Chen, B. Raghuraman, I. Raw, J. P. Delhomme, C. Chouzenoux, D. Pohl, Y. Manin, E. Rioufol, D. Swager, and J. Smith, 2002, An application of cemented resistivity arrays to monitor water flooding of the Mansfield Sandstone, Indiana, USA: SPE Reservoir Evaluation \& Engineering, 5, 447-454.

Dake, L. P., 1978, Fundamentals of reservoir engineering: Elsevier Science Publishing Company Ltd.

Gaudin, A. M. and D. W. Fuerstenau, 1955, Quartz flotation with anionic collectors: Transactions of the American Institute of Mining and Metallurgical Engineers, 7, 66-72.

Glover, P. W. J., M. J. Hole, and J. Pous, 2000, A modified Archie's Law for two conducting phases: Earth and Planetary Science Letters, 180, 369-383, doi: 10.1016/S0012-821X(00)00168-0

Guichet, X., L. Jouniaux, and J. P. Pozzi, 2003, Streaming potential of a sand column in partial saturation conditions: Journal of Geophysical Research Solid Earth : JGR, 108, 445-460, doi: 10.1029/2001JB001517.
Gulamali, M., E. Leinov, and M. D. Jackson, 2011, Self-potential anomalies induced by water injection into hydrocarbon reservoirs: Geophysics, $\mathbf{7 6}$, F283-F292, doi: 10.1190/1.3596010.

Hilland, J., 1997, Simple sensor system for measuring the dielectric properties of saline solutions: Measurement Science and Technology, 8, 901-910, doi: 10.1088/0957-0233/8/8/011.

Hunter, R. J., 1981, Zeta potential in colloid science: Academic Press.

Ishido, T., and H. Mizutani, 1981, Experimental and theoretical basis of electrokinetic phenomena in rock-water systems and its applications to geophysics: Journal of Geophysical Research, 86, 1763-1775, doi: 10.1029/JB086iB03p01763.

Jaafar, M. Z., J. Vinogradov, and M. D. Jackson, 2009, Measurement of streaming-potential coupling coeffcient in sandstones saturated with high salinity $\mathrm{NaCl}$ brine: Geophysical Research Letters, 36, doi: 10.1029/ 2009GL040549.

Jackson, M. D., 2010, Multiphase electrokinetic coupling: Insights into the impact of fluid and charge distribution at the pore scale from a bundle of capillary tubes model: Journal of Geophysical Research, 115.

Kestin, J., H. E. Khalifa, Y. Abe, C. E. Grimes, H. Sookiazian, and W. A. Wakeham, 1978, Effect of pressure on the viscosity of aqueous $\mathrm{NaCl}$ solutions in the temperature range $20-150^{\circ} \mathrm{C}$ title: Journal of Chemical and Engineering Data, 23, 328-336, doi: 10.1021/ je60079a011.

Kirby, B. J., and E. F. Hasselbrink, 2004, Zeta potential of microfluidic substrates: 1 . Theory, experimental techniques, and effects on separations: Electrophoresis, 25, 187-202, doi: 10.1002/(ISSN)1522-2683.

Kosmulski, M., 1996, Adsorption of cadmium on alumina and silica: Analysis of the values of stability constants of surface complexes calculated for different parameters of triple layer model: Colloids and Surfaces A: Physicocemical and Engineering Aspects, 117, 201-214, doi: 10.1016/ 0927-7757(96)03706-5.

Leroy, P., A. Revil, A. Kemna, P. Cosenza, and A. Ghorbani, 2008, Complex conductivity of water-saturated packs of glass beads: Journal of Colloid and Interface Science, 321, 103-117, doi: 10.1016/j.jcis.2007.12.031.

Li, H., and P. L. de Bruyn, 1966, Electrokinetic and adsorption studies on quartz: Surface Science, 5, 203-220, doi: 10.1016/0039-6028(66) 90082-3.

Malmberg, C. G., and A. A. Maryott, 1956, Dielectric constant of water from $0^{\circ}$ to $100^{\circ} \mathrm{C}$ : Journal of Research of the National Bureau of Standards (United States), 56, 1-8.

Mavko, G., T. Mukerji, and J. Dvorkin, 2009, The rock physics handbook: Tools for seismic analysis of porous media, 2nd ed.: Cambridge University Press.

Orr, J., V. Fabry, O. Aumont, L. Bopp, S. Doney, R. Feely, A. Gnanadesikan, N. Gruber, A. Ishida, F. Joos, R. Key, K. Lindsay, E. Maier-Reimer, R. Matear, P. Monfray, A. Mouchet, R. Najjar, G. Plattner, K. Rodgers, C. Sabine, J. Sarmiento, R. Schlitzer, R. Slater, I. Totterdell, M. Weirig, Y. Yamanaka, and A. Yool, 2005, Anthropogenic ocean acidification over the twenty-first century and its impact on calcifying organisms: Nature, 437, 681-686.

Piggott, M. D., G. J. Gorman, C. C. Pain, P. A. Allison, A. S. Candy, B. T. Martin, and M. R. Wells, 2008, A new computational framework for multi-scale ocean modelling based on adapting unstructured meshes: International Journal for Numerical Methods in Fluids, 56, 1003-1015, doi: 10.1002/(ISSN) 1097-0363.

Pride, S. R., and F. D. Morgan, 1991, Electrokinetic dissipation induced by seismic-waves: Geophysics, 56, 914-925, doi: 10.1190/1.1443125.

Reppert, P. M., and F. D. Morgan, 2003a, Temperature-dependent streaming potentials: 1. Theory: Journal of Geophysical Research, 108, 2546, doi 10.1029/2002JB001754.

Reppert, P. M., and F. D. Morgan, 2003b, Temperature-dependent streaming potentials: 2. Laboratory: Journal of Geophysical Research Solid Earth, 108, 2547, doi: 10.1029/2002JB001755.

Revil, A., and P. W. J. Glover, 1997, Theory of ionic-surface electric conduction in porous media: Physical Review B, 55, 1757-1773, doi 10.1103/PhysRevB.55.1757.

Revil, A., N. Linde, A. Cerepi, D. Jougnot, S. Matthaei, and S. Finsterle, 2007, Electrokinetic coupling in unsaturated porous media: Journal of Colloid and Interface Science, 313, 315-327, doi: 10.1016/j.jcis.2007 .03 .037 .

Revil, A., P. A. Pezard, and P. W. J. Glover, 1999, Streaming potential in porous media 1 . Theory of the zeta potential: Journal of Geophysical Research Solid Earth, 104, 20021-20031, doi: 10.1029/1999JB900089.

Saunders, J. H., M. D. Jackson, and C. C. Pain, 2006, A new numerical model of electrokinetic potential response during hydrocarbon recovery: Geophysical Research Letters, 33, L15316, doi: 10.1029/ 2006GL026835.

Saunders, J. H., M. D. Jackson, and C. C. Pain, 2008, Fluid flow monitoring in oil fields using downhole measurements of electrokinetic potential Geophysics, 73, no. 5, E165, doi: 10.1190/1.2959139.

Schoen, J., 2004, Physical properties of rocks: Fundamentals and principles of petrophysics: Pergammon. 
Seidel, M. P., M. D. DeGrandpre, and A. G. Dickson, 2008, A sensor for in situ indicator based measurements of seawater $\mathrm{pH}$ : Marine chemistry, 109, 18-28, doi: 10.1016/j.marchem.2007.11.013.

Sen, P. N., and P. A. Goode, 1992, Influence of temperature on electric conductivity on shaly sands: Geophysics, 57, 89-96, doi: 10.1190/ 1.1443191.

Shook, M., D. C. Li, and L. W. Lake, 1992, Scaling immiscible flow through permeable media by inspectional analysis: In Situ, 16, 311-349.

Sill, W. R., 1983, Self-potential modeling from primary flow: Geophysics, 48, 76-86, doi: 10.1190/1.1441409.

Stogryn, A., 1971, Equations for calculating the dielectric constant of saline water: IEEE Transactions on Microwave Theory and Techniques, 19, 733-736, doi: 10.1109/TMTT.1971.1127617.

Telford, W. M., L. P. Geldart, and R. E. Sheriff, 1990, Applied geophysics, 2nd ed.: Cambridge University Press.
Uematsu, M., and E. U. Franck, 1980, Static dielectric constant of water and steam: Journal of Physical and Chemical Reference Data, 9, 1291-1306, doi: $10.1063 / 1.555632$

Vinogradov, J., M. Z. Jaafar, and M. D. Jackson, 2010, Measurement of streaming-potential coupling coeffcient in sandstones saturated with natural and artificial brines at high salinity: Journal of Geophysical Research, 115, B12204, doi: 10.1029/2010JB007593.

Vinogradov, J., and M. D. Jackson, 2011, Multiphase streaming potential in sandstones saturated with gas/brine and oil/brine during drainage and imbibition: Geophysical Research Letters, 38, L01301.

Wurmstich, B., and F. D. Morgan, 1994, Modeling of streaming potential responses caused by oil-well pumping: Geophysics, 59, 46-56, doi: $10.1190 / 1.1443533$.

Wyllie, M. R. J., 1951, An investigation of the electrokinetic component of the SP curve: Journal of Petroleum Technology, 3, 1. 